\title{
Application of the neural modelling method for the Solar radiation analysis in a number of cities in the Russian Federation for the solution of environmental problems
}

\author{
Larisa Haritonova ${ }^{1 *}$ \\ ${ }^{1}$ Volgograd State Technical University, 28 Lenin Avenue, Volgograd, 400005, Russia
}

\begin{abstract}
The paper gives the assessment of using the methods of data mining including the artificial neural networks (ANN) in researching solar radiation for various regions of the Russian Federation, in particular, such cities as: Astrakhan (latitude of 46.4) and Sochi (at the latitude 43.6) located in the south, in Vladivostok (latitude 43.1), Yuzhno-Sakhalinsk (latitude of 47) - in the south-east of the country, PetropavlovskKamchatsky (latitude of 53.3) - in the east, Petrozavodsk (latitude of 61) in the south-west, and in the Russian capital - Moscow (latitude of 55.7). A neural network model has been developed, the most significant 15 input variables have been determined, as well as hidden layers number and the number of neurons. The most optimum functions were chosen, including the Bayesian Regularization as the training functions, the function of gradient descent with regard for moments as the Learning Function, the hyperbolic tangent activation function was taken as an activation function and the Mean Square Error was taken as an execution function. The feedforward backprop function was applied. The equations of regression and the correlation parameters were obtained for the calculation of solar radiation. The presented work can be useful for developers of different types of electric and solar heating systems to determine the requiered parameters for solar radiation with regard to the large bulk of meteorological and geographic data for improving the environmental situation including in civil engineering and municipal economy.
\end{abstract}

\section{Introduction}

In accordance with "Russian Long-Term S \& T Foresight 2030" among of Priority thematic $\mathrm{S} \& \mathrm{~T}$ areas (priority research areas) were included the following ones: Data processing and analysis technologies; Predictive modeling and simulation; Preservation of environment and environmental safety; Efficient utilization of renewable energy sources.

Problems of ecology and environmental safety have recently acquired a global character. The elimination of some of them is possible by using solar radiation. In most localities, hydro-power plants, power stations working on the natural fuel, and atomic

\footnotetext{
*Corresponding author: haritonova410@yandex.ru
} 
power plants are a safe source of power. Negative effects of these means of power supply are among others air and noise pollution of the neighboring areas, fire risks, high fuel consumption, and chances of fuel spillage in its transportation. Huge problems for the environment can occur in emergency situations at atomic power stations. These factors are mostly determined by the fact that either out-dated equipment or nearing the end of its lifespan. One of the solutions of the problems can be application of renewable energy sources, in particular, solar power, since solar power is the most perspective and clean energy source. Especially, it is likely to succeed for remote areas. The coming power from the sun as radiation can be used in such types of solar systems as both electric and thermal ones. In this case, there is a possibility to preserve the purity of the environment, provide a balance between demand and supply of energy, and to solve at least a part of arising environmental problems.

For a wider application of the solar power, it is needed to predict the solar radiation which is possible by using the methods of data mining. The application of artificial neural networks (ANN) when studying processes of various physical nature guarantees good accuracy and a very slight error [1- 10]. The study [9] considered data of comparative analysis of several artificial neural network models, including the Feed-forward back propagation (FFB), with feed-forward network (FFN), the probabilistic neural network (PNN), the cascaded feed forward back propagation (CFB), the radial basis of neural network (RBNN), the Elman back propagation neural network (ELM), and others. It was revealed that the selection of a parameters is very important for a higher accuracy of the artificial neural networks models. The greatest advantage of the artificial neural networks compared to other simulation methods is their ability to simulate non-linear complex processes without data on the form of the connection between input and output data. The publication data analysis [10] shows that the ANN models enable to predict solar radiation in a more accurate way than statistic, linear, non-linear, and fuzzy logical models. Here with, the accuracy of the prediction model for solar radiation depends largely upon the applied calculation algorithms, the network geometry as well as the number and the set of input parameters. As is shown in this same work [10], compared to other empirical models, the ANN enables to take into account numerous meteorological factors which provides higher safety and accuracy of calculations.

According to studies [7, 11], the choice of necessary geographic and meteorological variables as input data for the ANN models are an understudied research element. In the further work [8], such input variables as latitude, longitude, maximum and minimum temperatures, hours of sunshine were used. The study [9] states that the input variables greatly influence the accuracy of the ANN model prediction. A definite combination of the considered input data will look in its own way for each corner of the Earth.

Different authors choose the input variables for the ANN models using various combinations of geographic and meteorological data. There are studies where the input variables are presented for Turkey, India, China, Nigeria, Saudi Arabia, Iran, Spain, et al. There are no meteorological stations in some regions of the world. In most studies, the number of the input variables is limited by the availability of these data for a researcher and usually makes from 2 to 9 [11].

The Russian Federation has rather few studies for the solar radiation prediction. Therefore, the object of the study was to choose available initial data as the input variables, to develop a neural network geometry, to select the best Training, Learning, Activation and Execution functions. Later, it is planned to obtain regression equations and the correlation parameters to compute the solar radiation, to perform the output evaluation, and to formulate problems for the further continuation of studies. 


\section{Materials and Methods}

To carry out the analysis of photovoltaic systems, it is proposed to study the ANN for the insolation modeling on the territory of the Russian Federation. The application of the ANN will be studied to analyze the solar radiation in the cities of the Russian Federation such as: Astrakhan (latitude of 46.4 north) and Sochi ( latitude 43.6 north) - located in the south, in Vladivostok (latitude 43.1 north), Yuzhno-Sakhalinsk (latitude 47 north) - in the south-east of the country, Petropavlovsk-Kamchatsky (latitude 53.3 north) - in the east, Petrozavodsk (latitude 61 north)- in the north-west, and in the nation's capital - in Moscow (latitude 55.7 north). As the target data, the value of the solar radiation $\left(\mathrm{kWh} / \mathrm{m}^{2}\right)$ has been borrowed from [12].

The following input variables was applied:

- months (January -December (and yearly));

the volume of the solar radiation $\left(\mathrm{kWh} / \mathrm{m}^{2}\right)$ per

- vertical panel;

- horizontal vertical panel;

- panel slope to 50 degrees in Vladivostok and Petropavlovsk_-Kamchatsky; 45 degrees in Yuzhno-Sakhalinsk and Petrozavodsk; 40 degrees in Moscow; 35 degrees in the cities of

Sochi and Astrakhan;

- rotation of the panel around the polar axis;

- the longitude of each city;

- the latitude on which the cities are located;

- average monthly temperature, $\left({ }^{0} \mathrm{C}\right)$;

- air pressure;

- number of cloudy days per month (year);

- number of days when precipitation was observed;

- wind (average);

- clear days number during a corresponding month;

- maximum and minimum temperatures during a corresponding month, $\left({ }^{0} \mathrm{C}\right)$.

The architecture of the neural network has been developed, shown in Fig.1. The Matrix was as follows $15 \times 364$ - for the input variables, $1 \times 364$ - for the target ones. In the course of studies, the number of Epochs was assumed equaling 2000. Fig.2. presents a performance chart (the Mean Square Error and the number of epochs) for the ANN network geometry in Fig. 1.

It was obtained that the application of the Bayesian Regularization function makes the most sense as a Training function, the function of gradient descent with regard to moments as the learning function, the hyperbolic function as the activation function, the Mean Square Error - as the Execution function. It was used a feed-forward backdrop.

Fig.3,4,5 present the comparative diagram, the radar diagram, and the reverse radar plot for the comparison of the target and the output computed with the ANN network geometry (15-15-1-1) (in Fig. 1). In Fig.3, a logarithmic scale at the y-axis was used in the diagram.

The regression equations and the correlation coefficients in Training, Validation, Test, and All are presented in Fig.6. 


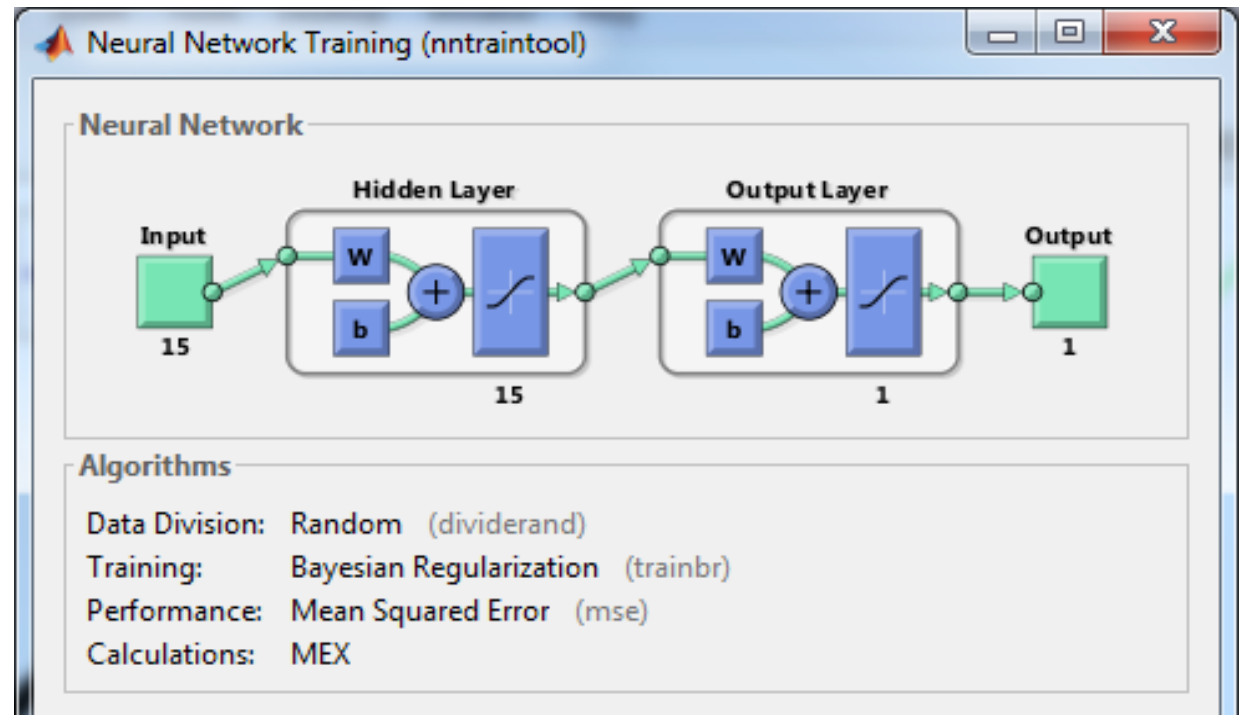

Fig. 1. The geometry network and some used algorithms of the designed neural network.

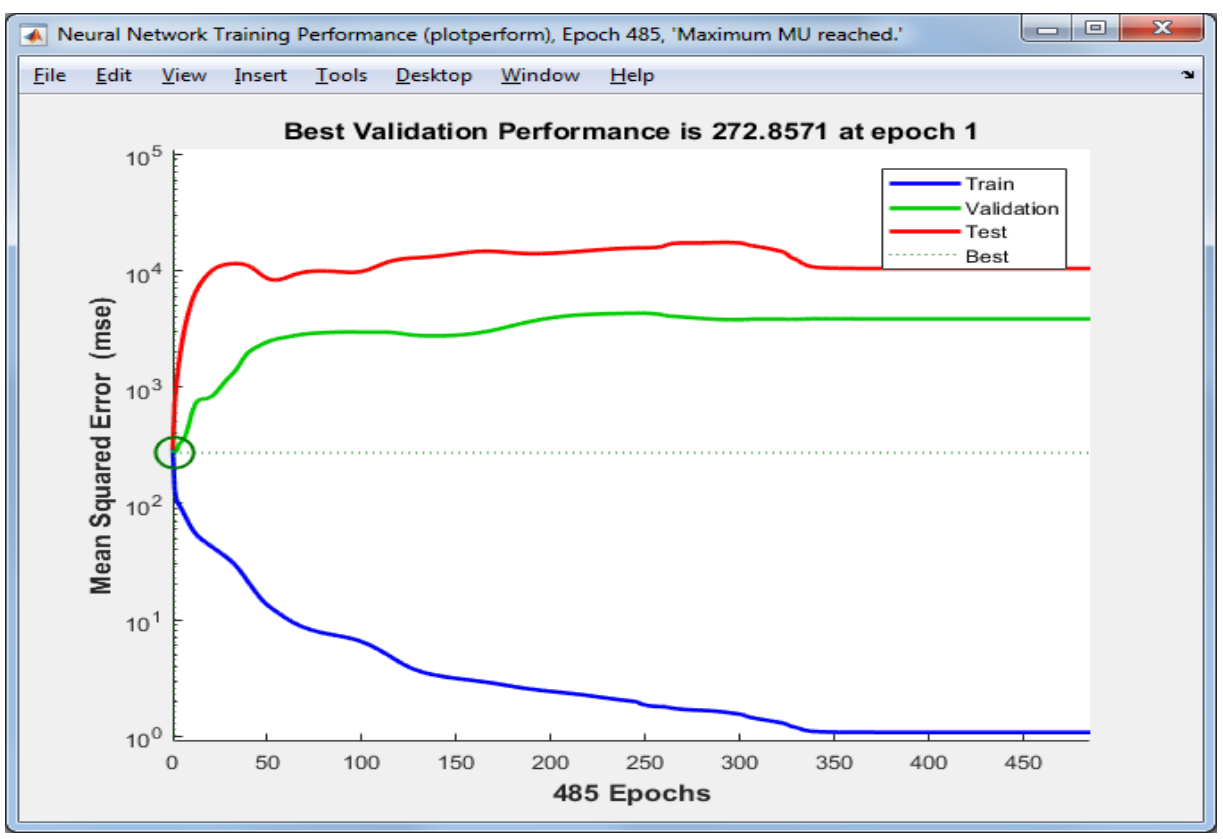

Fig. 2. The performance plot of the ANN model during training. 


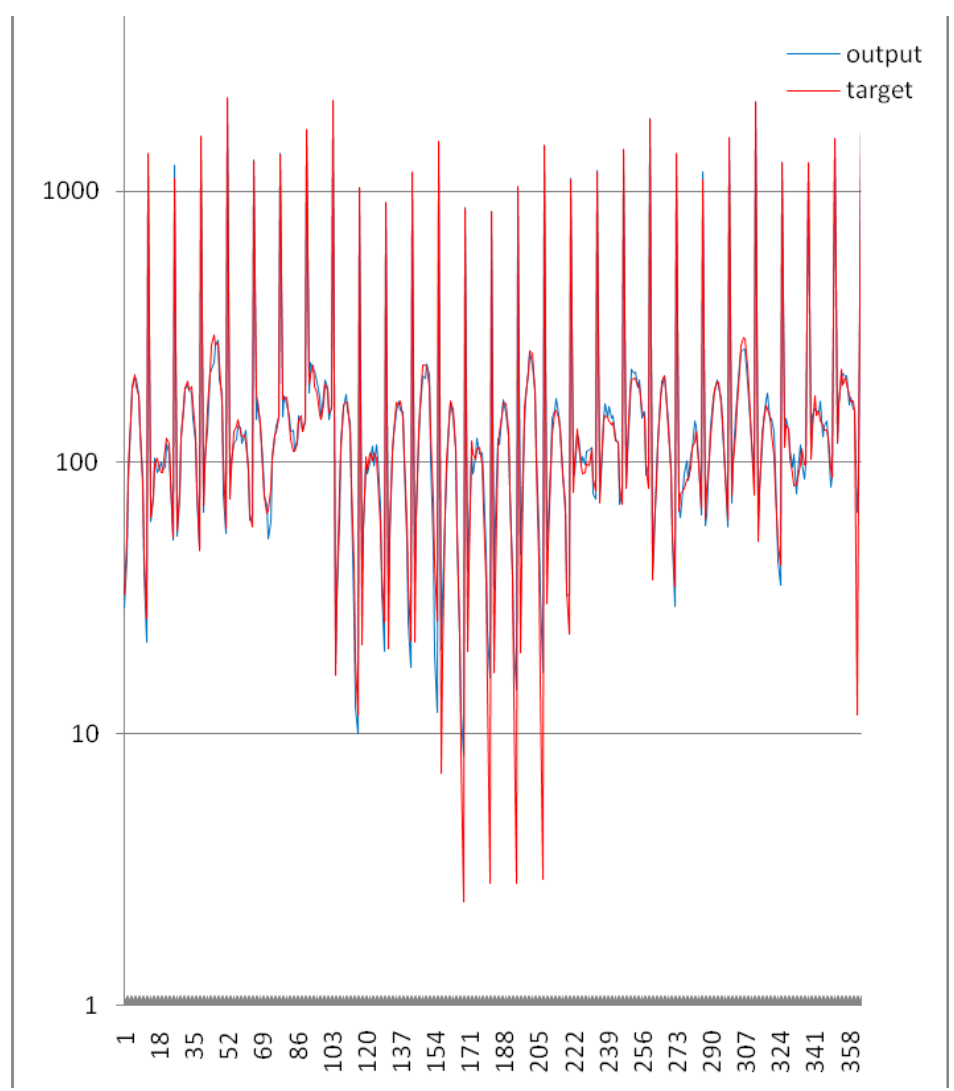

Fig. 3. The diagram of comparison for the target and the output, computed with the ANN network geometry (15-15-1-1) (in Fig. 1).

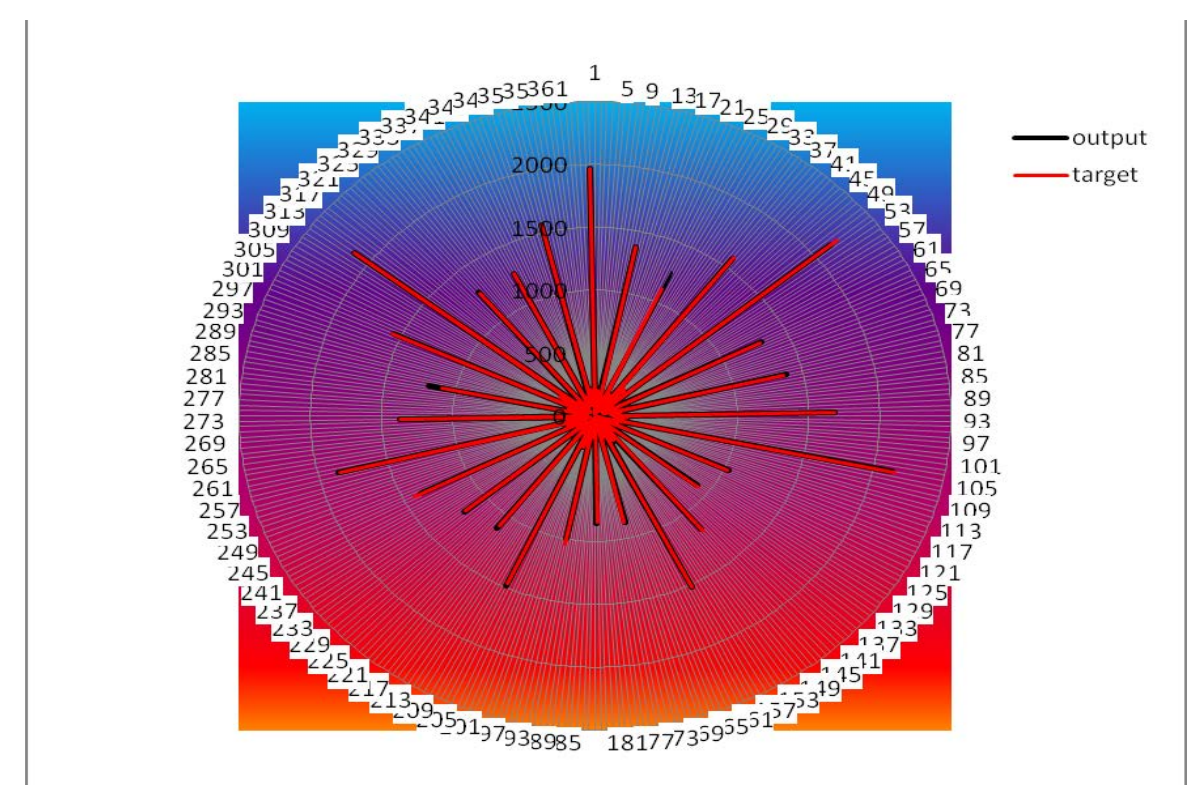

Fig. 4. Radar diagram where the comparison between the target and the output is given, computed with the ANN network architecture (15-15-1-1). 


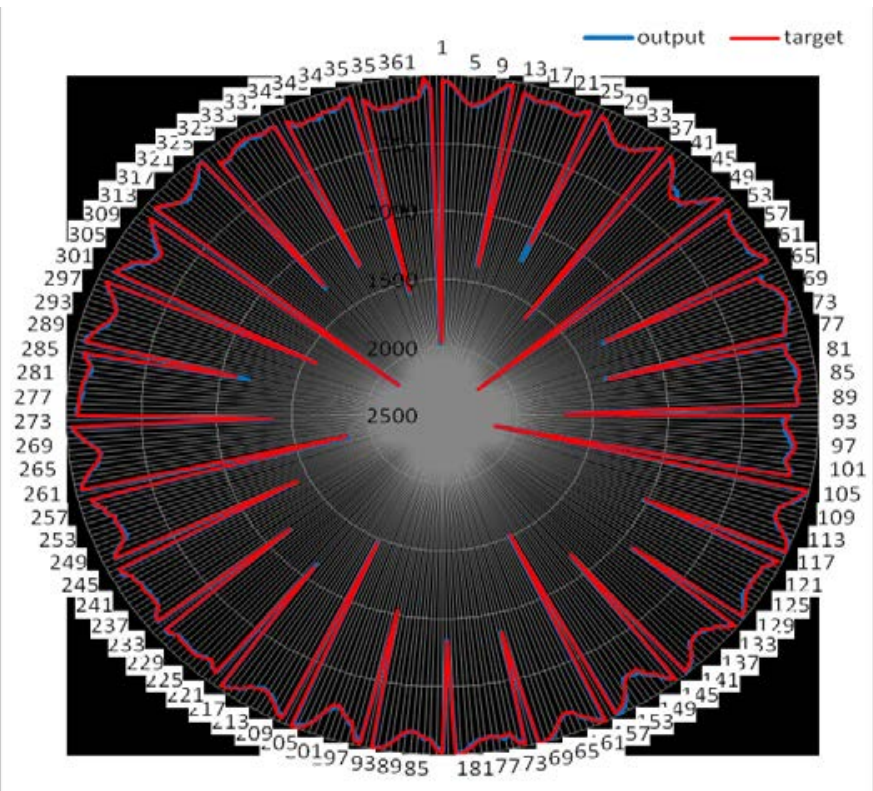

Fig. 5. Reverse radar diagram where the comparison between the target and the output is presented, computed with the ANN network architecture (15-15-1-1).

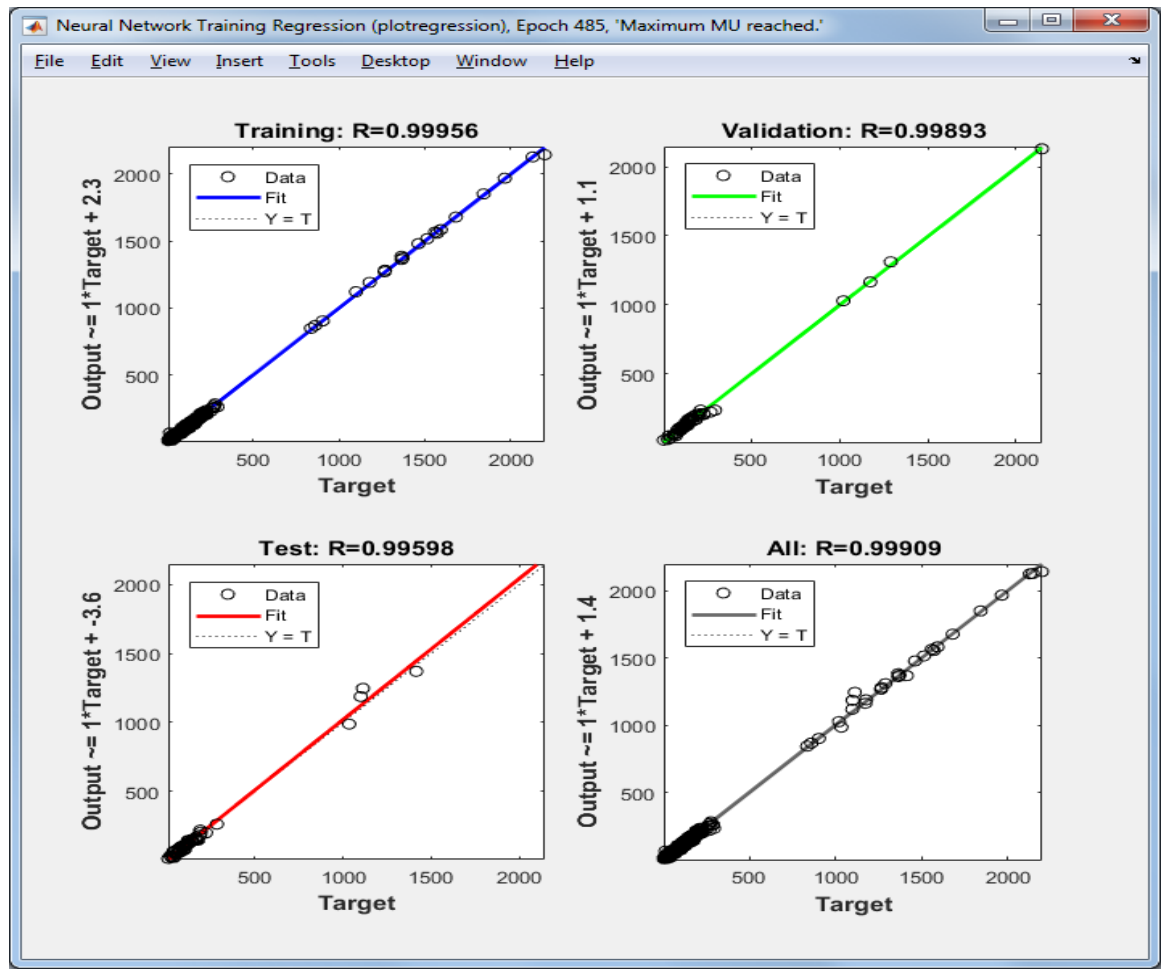

Fig. 6. Regression equations and correlation coefficients in Training, Validation, Test, and All when applying the neural network geometry (15-15-1-1). 


\section{Summary}

As follows from the analysis of the obtained results, the developed ANN model very accurately predicts the solar radiation in various climatic conditions and for different regions in the Russian Federation.

The presented study can help developers of various types of electric and thermal solar systems to determine the required parameters of the solar radiation with regard to a great amount of meteorological and other data. In the future, the study of practicability of data normalization is of definite interest as well as studies on the impact of various input data on the obtained results.

\section{References}

1. H. Malik, M.Singh, Applications of Artificial Intelligence Techniques in Engineering. Advances in Intelligent Systems and Computing, 697, 32-42 (2019)

2. L. Haritonova, Advances in intelligent systems and computing, 692, 700-709 (2018)

3. L.Haritonova, Neural Modeling of the Energy Efficiency Factor for Recuperators (Heat Exchangers) Using Impinging Jets for the Metallurgical Productions and Machine Building (Book Chapter), Lecture Notes in Mechanical Engineering. Book series Issue 9783319956299, 1269-1278 (Springer International Publishing, 2019)

4. L. Haritonova, International Journal of Engineering \& Technology, v. 7(2.23) (23), 440-442 (2018)

5. L. Haritonova, Procedia Engineering, 206, 1002-1008 (2017)

6. L. Haritonova, E3S Web of Conferences, 33, 02072207 (EDP Sciences, Les Ulis, France, 2018)

7. A.K. Yadav, S.S. Chandel, Renew Sustain Energy Rev, 33, 772-781 (2013)

8. A.K. Yadav, H.Malik, S.S. Chandel, Renew Sustain Energy Rev, 31, 509-519 (2014)

9. Y.Kashyap, A.Bansal, A.K.Sao, Renew Sustain Energy Rev, 49, 825-835 (2015)

10. Atika Qazi, H. Fayaz, A. Wadi, Ram Gopal Raj, N.A. Rahim, Waleed Ahmed Khan, Journal of Cleaner Production, 104, 1-12 (2015)

11. A.K. Yadav, H. Malik, S.S. Chandel, Renewable and Sustainable Energy Reviews, 52(Elsevier), 1093-1106 (2015)

12. Solar batteries of the Russian manufacturer "SOLBAT" 2018 URL http://www.solbat.su/fotosis/general/ date of treatment 9.04.2019 